\title{
An Unusual Presentation of Concurrent Congenital Grouped Pigmentation of the Retina with Albinotic Spots
}

\author{
Meri Watanabe Shinji Makino Hironobu Tampo \\ Department of Ophthalmology, Jichi Medical University, Shimotsuke, Japan
}

\section{Key Words}

Grouped pigmentation · Albinotic spots · Retina

\begin{abstract}
A 10-year-old Japanese girl presented with multiple, small, flat, dark brown clusters of retinal pigment epithelium in both eyes. She had no other symptoms. The appearance was consistent with congenital grouped pigmentation of the retina or bear track spots. A unique coexisting feature was the presence of small, albinotic spots within the entire retina. Fluorescein angiography demonstrated a persistent hypofluorescence correlating with the grouped pigmentation of the retina and granular hyperfluorescence correlating with the albinotic spots. Her mother also showed irregular pigmentation and albinotic spots in both eyes. We describe an extremely rare case of congenital grouped pigmentation and albinotic spots occurring in the retina of the same individual.

(C) 2015 S. Karger AG, Basel
\end{abstract}

\section{Introduction}

Congenital grouped pigmentation of the retina or bear track spots is an uncommon anomaly characterized by multiple, grouped, sharply circumscribed, pigmented spots with no visual dysfunction $[1,2]$. Detection is usually coincidental during routine ocular examinations. Congenital albinotic spots of the retina or polar bear tracks are also an uncommon disorder typified by albinotic spots with no visual dysfunction $[2,3]$. Here we present an unusual case of congenital grouped pigmentation of the retina associated with albinotic spots in a 10-year-old Japanese girl.

KARGER 125/s $\quad \begin{aligned} & \text { Shinji Makino } \\ & 3311-1 \text { Yakushiji } \\ & \text { Shimotsuke, Tochigi 329-0498 (Japan) } \\ & \text { E-Mail makichan@jichi.ac.jp }\end{aligned}$


Watanabe et al.: An Unusual Presentation of Concurrent Congenital Grouped Pigmentation of the Retina with Albinotic Spots

\section{Case Report}

A 10-year-old asymptomatic Japanese girl was referred to our clinic for an ophthalmological examination of bilateral fundus discoloration. Her medical and personal histories were unremarkable and her physical examination revealed no abnormalities. Her visual acuity was 1.2 in both eyes. The anterior segment of both eyes was normal. Ophthalmoscopy of both eyes revealed multiple, small, flat, pigmented spots in the peripheral retina (fig. 1a, b), consistent with a grouped pigmentation of the retina or bear track spots. As a unique coexisting feature, small albinotic spots were identified in the posterior pole (fig. $2 \mathrm{a}, \mathrm{b}$ ) and the peripheral retina (fig. $1 \mathrm{a}, \mathrm{b}$ ). The albinotic spots were predominantly detected at the posterior pole of both fundi (fig. 2a, b). Fluorescein angiography demonstrated a persistent hypofluorescence correlating with grouped pigmentation of the retina (fig. 1c, d) and granular hyperfluorescence correlating with the albinotic spots (fig. 1c, d, fig. 2c, d). Ophthalmoscopic examination of the girl's mother revealed albinotic spots in the posterior pole (fig. 3a, b) and an irregular pigmentation in the peripheral retina (fig. 3c, d) in both eyes. Although the patient's mother has undergone a colonoscopy to examine her adenomatous polyposis, abnormal findings were not detected. In addition, a genetic consultation was not performed in this case.

\section{Discussion}

Congenital grouped pigmentation of the retina is characterized by multiple, grouped, sharply circumscribed, pigmented spots. Congenital grouped albinotic spots are characterized by multiple, variably sized, sharply circumscribed, placoid, white lesions. In our present case, the size of albinotic spots was smaller than that of the pigmented spots, and the albinotic spots organized in patterns resembling drusen. However, these fundus changes were very similar to those observed in the following 2 reports. Turell et al. [3] described a case of grouped pigmented lesions with nonpigmented, punctate lesions located within the macula. Kadoi et al. [2] described congenital grouped pigmentation of the retina in a girl and congenital albinotic spots of the retina in her sister. Their fundus changes were very similar to those observed in the present case. Therefore, we considered this condition as congenital grouped pigmentation and albinotic spots in the retina. To the best of our knowledge, this is the second report of 2 entities, i.e., congenital grouped pigmentation and albinotic spots in the retina, occurring simultaneously in the same individual.

Grouped pigmentation of the retina is considered to be sporadic, although familial occurrences have rarely been reported. Renardel de Lavalette et al. [4] reported a familial case of a mother and daughter who showed an autosomal dominant inheritance, while De Jong and Delleman [5] described a father and son with the disease. Similarly, grouped albinotic spots of the retina are also considered to be sporadic, although familial occurrences have rarely been reported. Arana et al. [6] reported a familial case of a mother and 3 daughters.

In conclusion, although our current findings were based on a single case, additional cases and genetic examination are needed to definitively characterize these rare and unusual associations between congenital grouped pigmentation and albinotic spots in the retina.

\section{Disclosure Statement}

The authors have no financial or proprietary interests related to this paper. 
Case Reports in

Ophthalmology

\begin{tabular}{l|l}
\hline \multicolumn{2}{l}{ Case Rep Ophthalmol 2015;6:39-43 } \\
\hline DOI: 10.1159/000375525 & $\begin{array}{l}\text { ○ 2015 S. Karger AG, Basel } \\
\text { www.karger.com/cop }\end{array}$ \\
\hline
\end{tabular}

Watanabe et al:: An Unusual Presentation of Concurrent Congenital Grouped Pigmentation of the Retina with Albinotic Spots

\section{References}

1 Yoshida T, Adachi-Usami E, Kimura T: Three cases of grouped pigmentation of the retina. Ophthalmologica 1995;209:101-105.

2 Kadoi C, Hayasaka S, Hayasaka Y, Matsumoto M, Nagaki Y: Bilateral congenital grouped pigmentation of the retina in one girl and bilateral congenital albinotic spots of the retina in her sister. Retina 1999;19:571-572.

3 Turell ME, Leonardy NJ, Singh AD: A unique presentation of grouped congenital hypertrophy of the retinal pigment epithelium. Ophthalmic Genet 2011;32:162-164.

4 Renardel de Lavalette VW, Cruysberg JR, Deutman AF: Familial congenital grouped pigmentation of the retina. Am J Ophthalmol 1991;112:406-409.

-5 De Jong PTVM, Delleman JW: Familial grouped pigmentation of the retinal pigment epithelium. Br J Ophthalmol 1988;72:439-441.

-6 Arana LA, Sato M, Arana J: Familial congenital grouped albinotic retinal pigment epithelial spots. Arch Ophthalmol 2010;128:1362-1364.
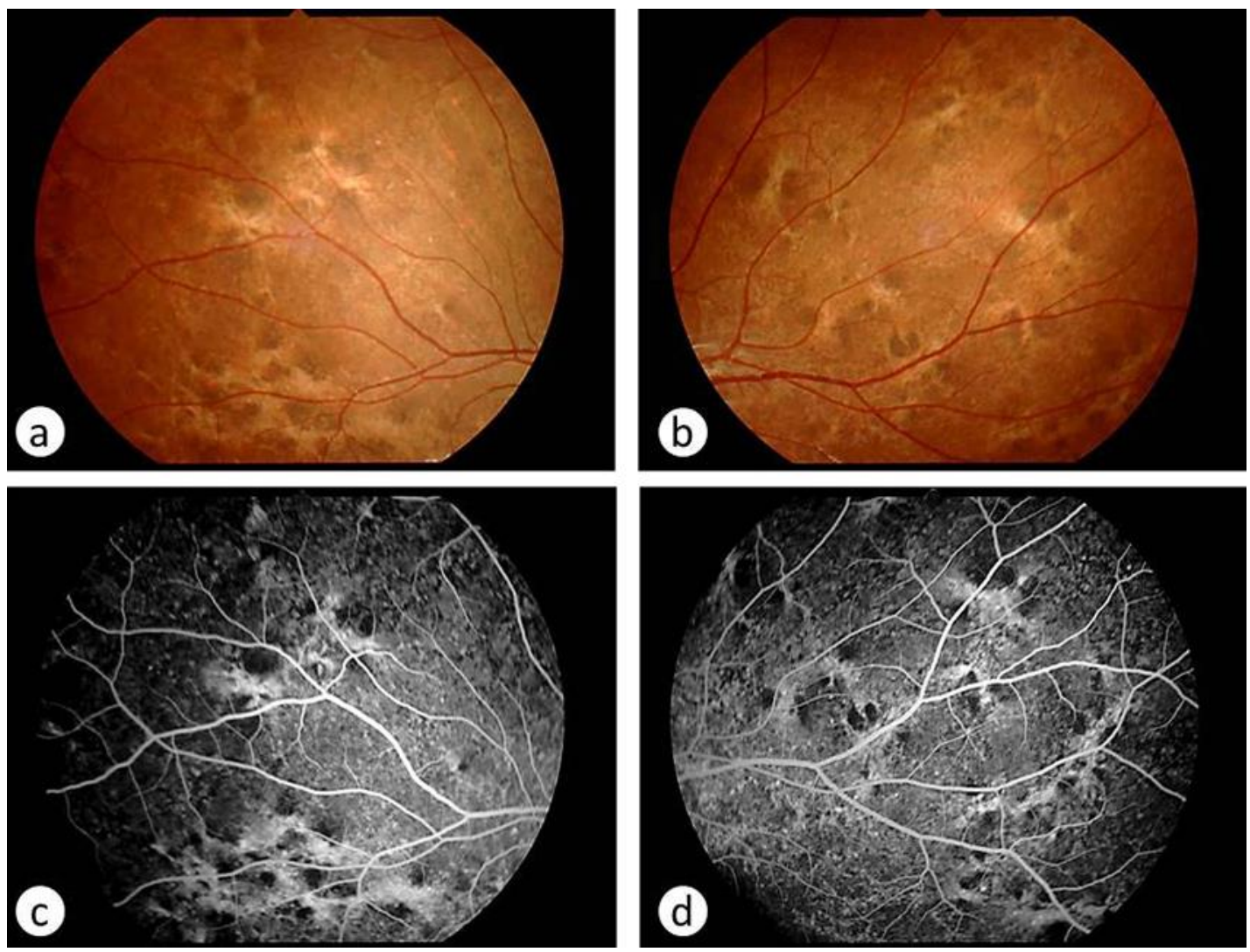

Fig. 1. Fundus photographs (a, b) and fluorescein angiography (c, d) of the peripheral retina demonstrating a predominance of grouped pigmentation in the right $(\mathbf{a}, \mathbf{c})$ and left $(\mathbf{b}, \mathbf{d})$ eye. Fluorescein angiography shows hypofluorescence correlating with grouped pigmentation. 


\section{Case Reports in Ophthalmology}

\begin{tabular}{l|l}
\hline \multicolumn{2}{l}{ Case Rep Ophthalmol 2015;6:39-43 } \\
\hline DOI: 10.1159/000375525 & $\begin{array}{l}\text { ○ 2015 S. Karger AG, Basel } \\
\text { www.karger.com/cop }\end{array}$ \\
\hline
\end{tabular}

Watanabe et al.: An Unusual Presentation of Concurrent Congenital Grouped Pigmentation of the Retina with Albinotic Spots
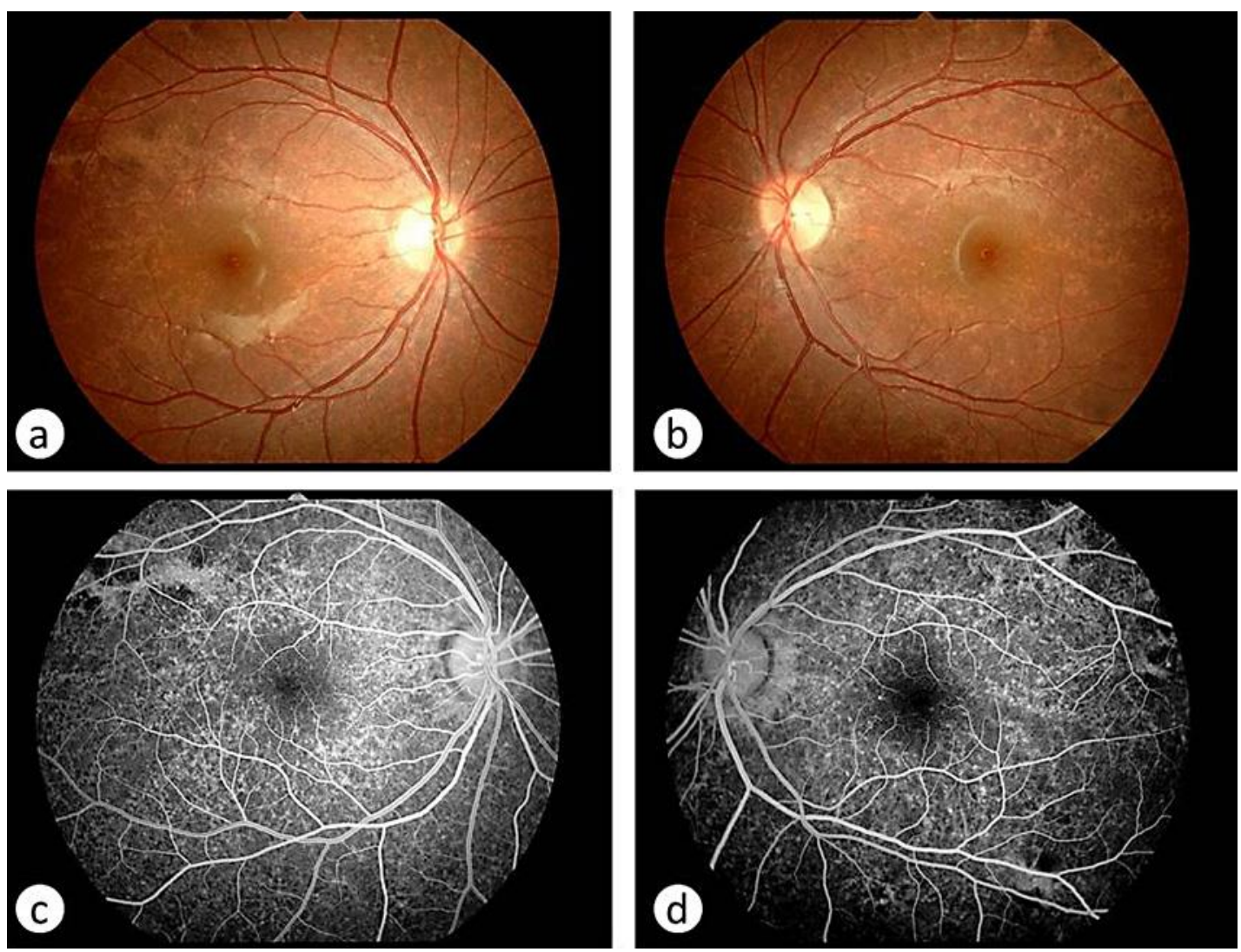

Fig. 2. Fundus photographs (a, b) and fluorescein angiography $(\mathbf{c}, \mathbf{d})$ of the posterior pole demonstrating a predominance of small albinotic spots in the right $(\mathbf{a}, \mathbf{c})$ and the left $(\mathbf{b}, \mathbf{d})$ eye. Fluorescein angiography shows granular hyperfluorescence correlating with albinotic spots. 

Watanabe et al.: An Unusual Presentation of Concurrent Congenital Grouped
Pigmentation of the Retina with Albinotic Spots
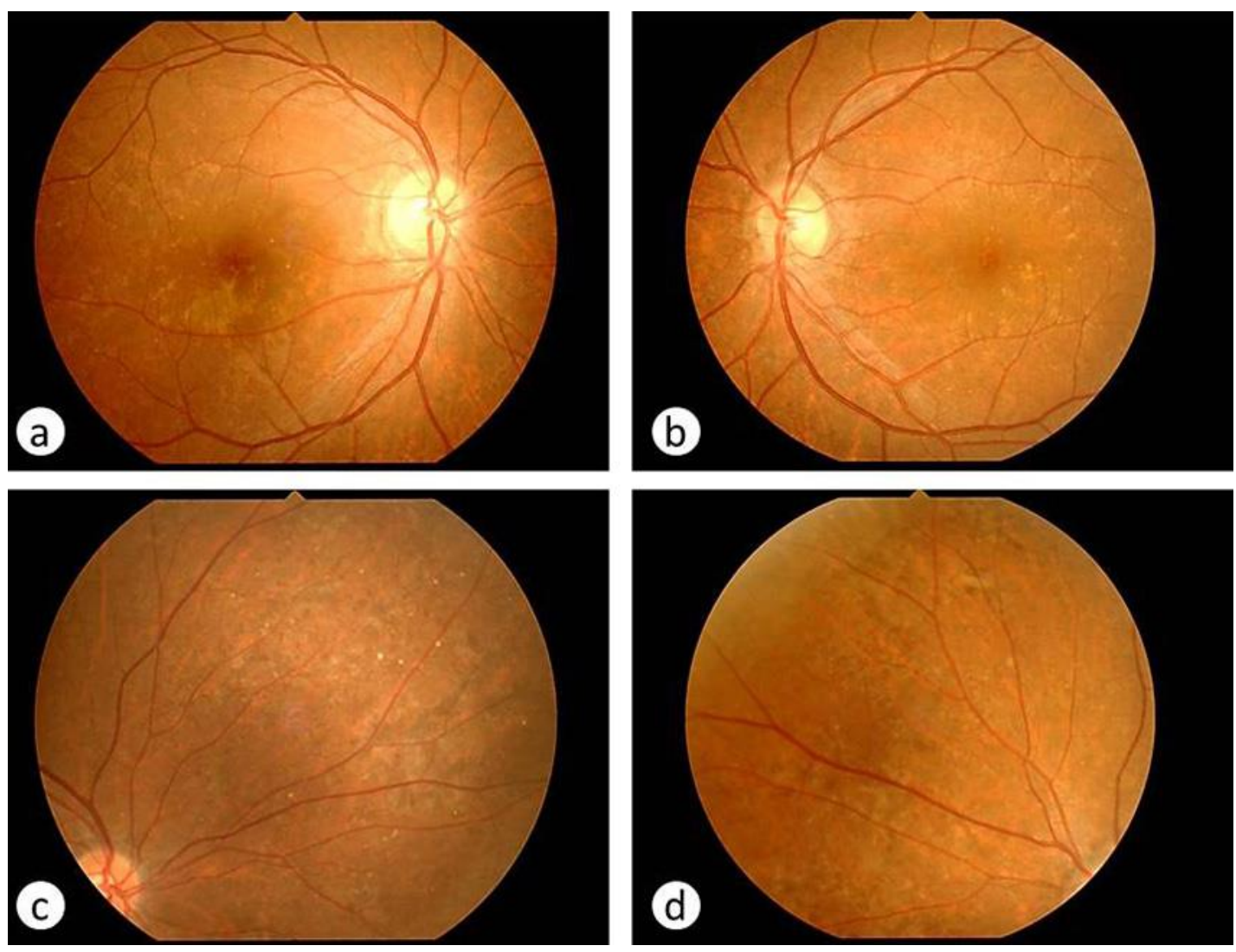

Fig. 3. Right (a, c) and left (b, d) fundus photographs of the posterior pole (a, b) demonstrating albinotic spots, and the peripheral retina (c, d) demonstrating irregular pigmentation. 